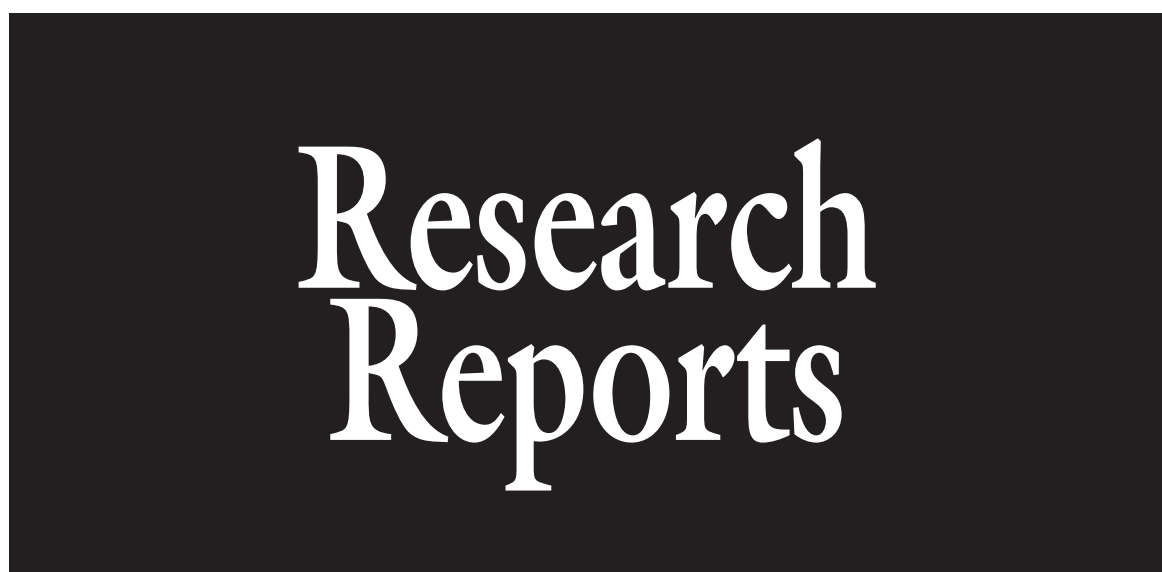

\section{Seeded Bermudagrass Tolerance to Simulated Athletic Field Traffic as Affected by Cultivars and Trinexapac-ethyl}

\author{
David W. Williams ${ }^{1}$, Paul B. Burrus, and Kenneth L. Cropper
}

AdDitional INDEX wORDs. Cynondon dactylon, plant growth regulators, sports fields, turfgrass wear, Brinkman traffic simulator

\begin{abstract}
SUMMARY. Use of seeded-bermudagrasses (Cynondon dactylon) is expanding rapidly, especially on high-use athletic fields. Previous work has defined significant differences in several parameters among cultivars. Experiments were conducted in Lexington, KY, in 2004 and 2005 to test the tolerance of the cultivars Riviera, Princess, Transcontinental, Savannah, Yukon, and the experimental line SWI 1012, with and without applications of trinexapac-ethyl to simulated athletic traffic. Plots were established in June of each year and managed as athletic field turf. Simulated traffic was applied using a Brinkman traffic simulator during high school football seasons in Kentucky at a level roughly equivalent to three games per week.

Percentage of bermudagrass cover was visually rated weekly during the trafficking periods each year. Turfgrass quality was rated once before beginning traffic treatments each year. There were no consistent significant interactions $(P>0.05)$ among trinexapac-ethyl treatments and cultivars in either year of the study for either response variable. The main effect of cultivars was highly significant $(P<0.0001)$ for percentage of bermudagrass cover in both years of the study. Among cultivars, the ranges of percentage of bermudagrass cover at the end of the trafficking periods were $10.2 \%$ to $39.2 \%$ and $43.3 \%$ to $76.7 \%$ in 2004 and 2005 , respectively. The main effects of trinexapac-ethyl on percentage of bermudagrass cover were significant $(P<$ $0.0052)$ and more pronounced in 2004. Significant differences $(P<0.0200)$ were also recorded in 2005. Applications of trinexapac-ethyl resulted in increased tolerance to simulated traffic and improved turfgrass quality. Under the conditions of this study, data indicate that both cultivars and regular applications of trinexapac-ethyl have significant effects on overall turfgrass quality and the tolerance of these seeded bermudagrasses to simulated traffic.
\end{abstract}

$\mathrm{M}$ any athletic field managers use bermudagrass based on its quality characteristics and production of rhizomes and stolons that allow it to spread naturally

\footnotetext{
Department of Plant and Soil Sciences, University of Kentucky, Room 329, Plant Science Building, Lexington, KY 40546-0312

Submitted as manuscript 09-06-013 from the University of Kentucky Agricultural Experiment Station.

${ }^{1}$ Corresponding author. E-mail: david.williams@ uky.edu.
}

and provide a superior playing surface when properly managed. Historically, bermudagrass was vegetatively propagated, but many newer-seeded cultivars exhibit excellent quality and have become popular alternatives to vegetatively propagated cultivars.

Wear stress occurs on all athletic fields but is often more severe in the center of football and soccer fields. The severity of damage depends on factors such as the number of events per season, the size of the athletes, and the soil moisture status during use (Powell, 2007). Traffic-stressed turf exhibits discoloration and bare areas that are unsightly and can contribute to increased player injuries. These stressed areas often require some level of annual renovation to provide an acceptable playing surface in subsequent seasons.

Research has shown there are various methods of increasing wear tolerance in turfgrass. The use of cultivars that exhibit higher wear tolerance is one important way of reducing wear stress. As with other traits, turfgrasses differ not only among species in wear tolerance but among cultivars as well. Samaranayake et al. (2008) reported that creeping bentgrass (Agrostis stolonifera) and velvet bentgrass (Agrostis canina) differed in wear tolerance, with many velvet bentgrass cultivars tolerating stress better than creeping bentgrass cultivars. Bayrer (2006) reported significant differences among three seeded and one vegetative cultivar of bermudagrass under simulated high traffic regimes. Goddard et al. (2008) found differences in wear tolerance among bermudagrasses, with 'Riviera' and 'Tifway' outperforming 'Quickstand' and they also found that applications of crumb rubber improved wear tolerance.

It is believed the effects of the plant growth regulator, trinexapacethyl (TE) could also be positive. The application of TE on bermudagrass has become a common practice based on research over the past decade showing numerous beneficial effects. Studies on dwarf-type bermudagrass (Cynodon

\begin{tabular}{llll}
\hline $\begin{array}{l}\text { Units } \\
\text { To convert U.S. to SI, } \\
\text { multiply by }\end{array}$ & U.S. unit & SI unit & $\begin{array}{l}\text { To convert SI to U.S., } \\
\text { multiply by }\end{array}$ \\
\hline 0.3048 & $\mathrm{ft}$ & $\mathrm{m}$ & 3.2808 \\
9.3540 & gal/acre & $\mathrm{L} \cdot \mathrm{ha}^{-1}$ & 0.1069 \\
2.54 & inch(es) & $\mathrm{cm}$ & 0.3937 \\
25.4 & inch(es) & $\mathrm{mm}$ & 0.0394 \\
1.1209 & lb/acre & $\mathrm{kg} \cdot \mathrm{ha}^{-1}$ & 0.8922 \\
6.8948 & psi & $\mathrm{kPa}$ & 0.1450
\end{tabular}


Table 1. Total precipitation, deviation from normal precipitation, cumulative total precipitation, and cumulative departure from normal precipitation data collected at the University of Kentucky Agricultural Experiment Station in Lexington for the periods 1 June through 31 Oct. in 2004 and 2005.

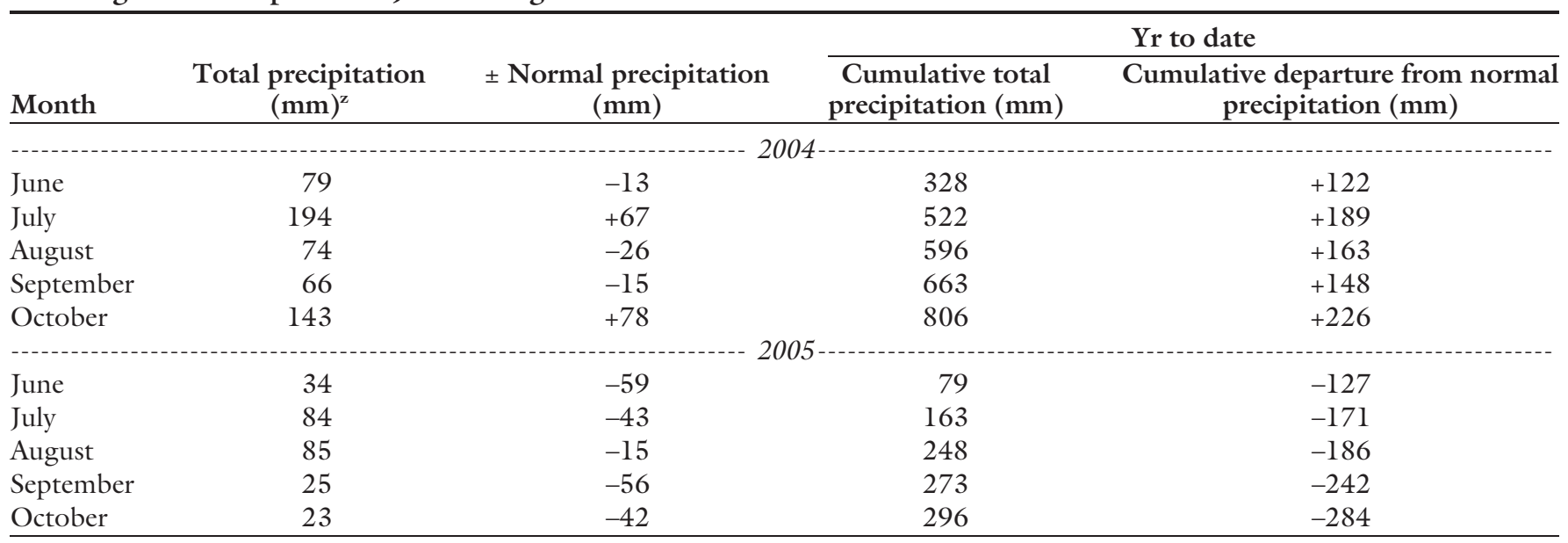

${ }^{\mathrm{z}} 1 \mathrm{~mm}=0.0394$ inch.

Table 2. Results of analysis of variance for turfgrass quality ratings as affected by applications of 0.09 lb/acre $\left(0.101 \mathrm{~kg} \cdot \mathrm{ha}^{-1}\right)$ a.i. trinexapac-ethyl (TE) and six bermudagrass cultivars (Riviera, Princess 77, Transcontinental, Savannah, Yukon, and SWI-1012) before being subjected to simulated athletic traffic with the Brinkman traffic simulator. Data were collected on 7 Sept. 2004 and 2 Sept. 2005.

\begin{tabular}{lll}
\hline & \multicolumn{2}{c}{$P>\mathrm{F}$} \\
\cline { 2 - 3 } Source & $\mathbf{2 0 0 4}$ & $\mathbf{2 0 0 5}$ \\
\hline Block $^{\mathrm{z}}$ & 0.2531 & 0.0782 \\
TE & 0.0001 & 0.0001 \\
Cultivar & 0.0001 & 0.0349 \\
TE $\times$ cultivar & 0.0217 & 0.7877 \\
$\mathrm{cv}(\%)^{\mathrm{y}}$ & 11.0 & 12.3 \\
\hline
\end{tabular}

${ }^{\mathrm{z}}$ Block is the source of variation provided by replications.

${ }^{y}$ Coefficient of variation.

dactylon $\times$ C. transvaalensis) commonly used on golf course greens have shown TE to increase stolon and rhizome mass, stand color, nutrient retention and use efficiency, root growth, and golf ball roll while decreasing clippings from mowing (McCullough et al., 2006a, 2006b, 2007). Studies on other cultivars have shown TE to increase the total green period of bermudagrass so that it stays green longer in the autumn and comes out of dormancy quicker in the spring, and to increase stolons, density, and quality at higher temperatures (Ervin and Zhang, 2007; Fagerness et al., 2002; Richardson, 2002).

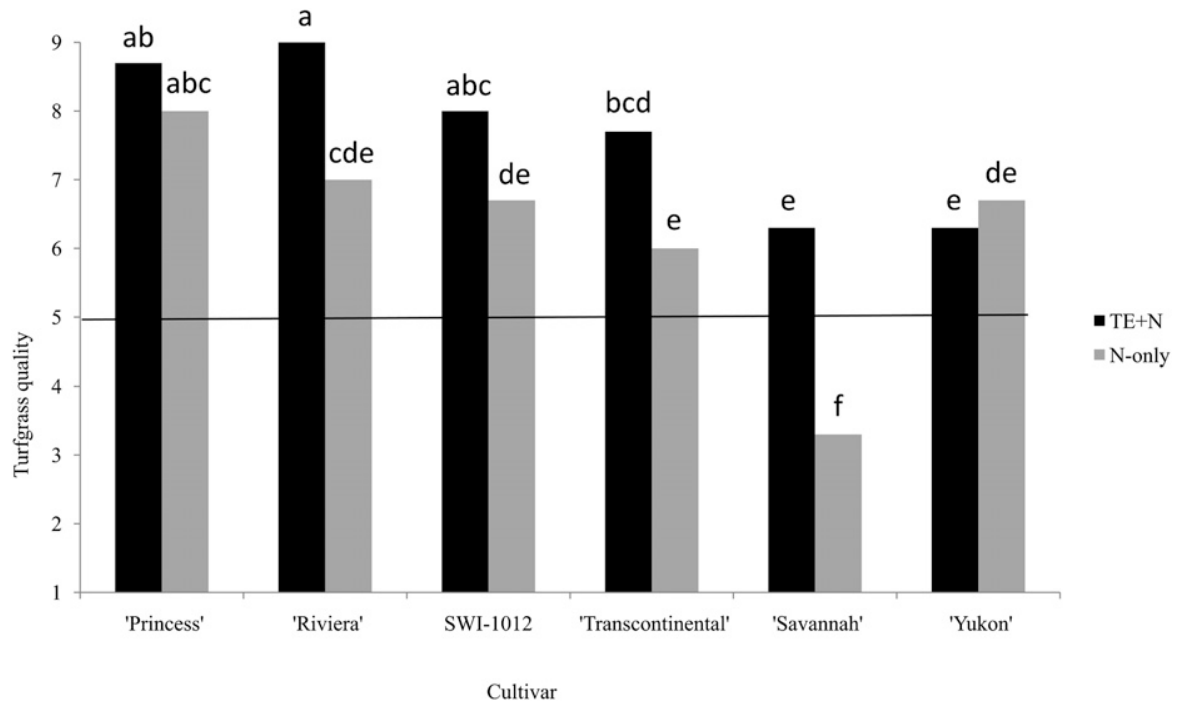

Fig. 1. The effects of six cultivars and applications of $0.09 \mathrm{lb} / \mathrm{acre}\left(0.101 \mathrm{~kg} \cdot \mathrm{ha}^{-1}\right)$ a.i. trinexapac-ethyl (TE) every 3 weeks throughout the 2004 growing season on bermudagrass turfgrass quality rated on a scale of 1 through 9 , where $1=100 \%$ dead turf, $9=$ optimum quality, and $5=$ minimum acceptable quality. All plots received nitrogen $(\mathrm{N})$ applied at $44 \mathrm{lb} /$ acre $\left(49.3 \mathrm{~kg} \cdot \mathrm{ha}^{-1}\right) \mathrm{N}$ every 2 weeks. Ratings were collected on 7 Sept. 2004. Horizontal line indicates the minimum acceptable quality rating of " 5 ." Bars labeled with the same letters are not significantly different at $P>0.05$.

Previous studies have not evaluated several of the present commercially available cultivars of seeded bermudagrass. Additionally, the direct effects of TE applications on traffic tolerance among cultivars have not been elucidated. The objective of this study was to investigate the tolerance of seeded bermudagrass cultivars with and without applications of TE to simulated athletic traffic. In particular, this work is aimed at evaluation of these treatments under conditions similar to high-use athletic facilities in the transitional climatic zone.

\section{Materials and methods}

These studies were conducted in 2004 and 2005 at the University of Kentucky Agricultural Experiment Station in Lexington. The soil was a Maury silt loam (fine, mixed, mesic typic Paleudalf) with a $\mathrm{pH}$ of 6.3 and $4.1 \%$ organic matter content in the top $5 \mathrm{~cm}$. Plot areas were fumigated with methyl-bromide before trial 
Table 3. Results of analysis of variance for visual estimations of percentage of bermudagrass cover for eight observation dates in 2004 and six observation dates in 2005 as affected by applications of $0.09 \mathrm{lb} / \mathrm{acre}\left(0.101 \mathrm{~kg} \cdot \mathrm{ha} \mathrm{a}^{-1}\right)$ a.i. trinexapac-ethyl (TE) and six bermudagrass cultivars (Riviera, Princess 77, Transcontinental, Savannah, Yukon, and SWI-1012) after initiation and during applications of simulated traffic treatments with the Brinkman traffic simulator. Traffic treatments equivalent to three games per week began on 6 Sept. 2004 and 7 Sept. 2005, and continued until 12 Nov. 2004 and 31 Oct. 2005.

\begin{tabular}{|c|c|c|c|c|c|c|c|c|}
\hline \multicolumn{9}{|c|}{ Observation date } \\
\hline Source & 15 Sept. & 27 Sept. & 5 Oct. & 12 Oct. & 19 Oct. & 25 Oct. & 3 Nov. & 12 Nov. \\
\hline Block $^{y}$ & 0.0381 & 0.3969 & 0.0029 & 0.0896 & 0.0514 & 0.2030 & 0.1013 & 0.0111 \\
\hline $\mathrm{TE}$ & 0.0013 & 0.0002 & 0.0057 & 0.0004 & 0.0052 & 0.0163 & 0.0017 & 0.0001 \\
\hline Cultivar & 0.0001 & 0.0001 & 0.0001 & 0.0001 & 0.0001 & 0.0002 & 0.0001 & 0.0001 \\
\hline \multicolumn{9}{|c|}{ Observation date } \\
\hline Source & 16 Sept. & 26 Sept. & 3 Oct. & 10 Oct. & 17 Oct. & 31 Oct. & & \\
\hline Block & 0.0969 & 0.0575 & 0.0331 & 0.6912 & 0.0691 & 0.1482 & & \\
\hline
\end{tabular}

${ }^{\mathrm{z}}$ Observations were collected about weekly after initiation of simulated traffic treatments.

Block is the source of variation provided by replications.

${ }^{x}$ Coefficient of variation.

establishment to eliminate competition from weeds.

Experimental design was a randomized complete block split plot with three replications. Whole plots were $6 \times 20 \mathrm{ft}$ and split plots were $6 \times$ $10 \mathrm{ft}$. Whole plot treatments were cultivar and split plot treatments were applications of TE or no TE. Six cultivars were evaluated: Princess 77, Riviera, Savannah, Transcontinental, Yukon, and an experimental line SWI1012. These cultivars were chosen to represent a range of known turfgrass quality traits from previous work (Morris, 2006). Of particular interest were differences in leaf texture and tiller density, with 'Princess 77' and 'Riviera' representing fine texture and high density, 'Transcontinental' being intermediate, and 'Savannah' and 'Yukon' exhibiting coarser texture and less tiller density (Morris, 2006). The experimental line SWI-1012 had exhibited quality traits similar to 'Transcontinental' in other work (not published), but had not been evaluated as fully as had the named cultivars.

The experiment was designed to generally emulate most common, public athletic fields that tend to receive excessive use and traffic (e.g., county high schools). Plots were seeded at a rate of $22 \mathrm{lb} /$ acre of pure live seed

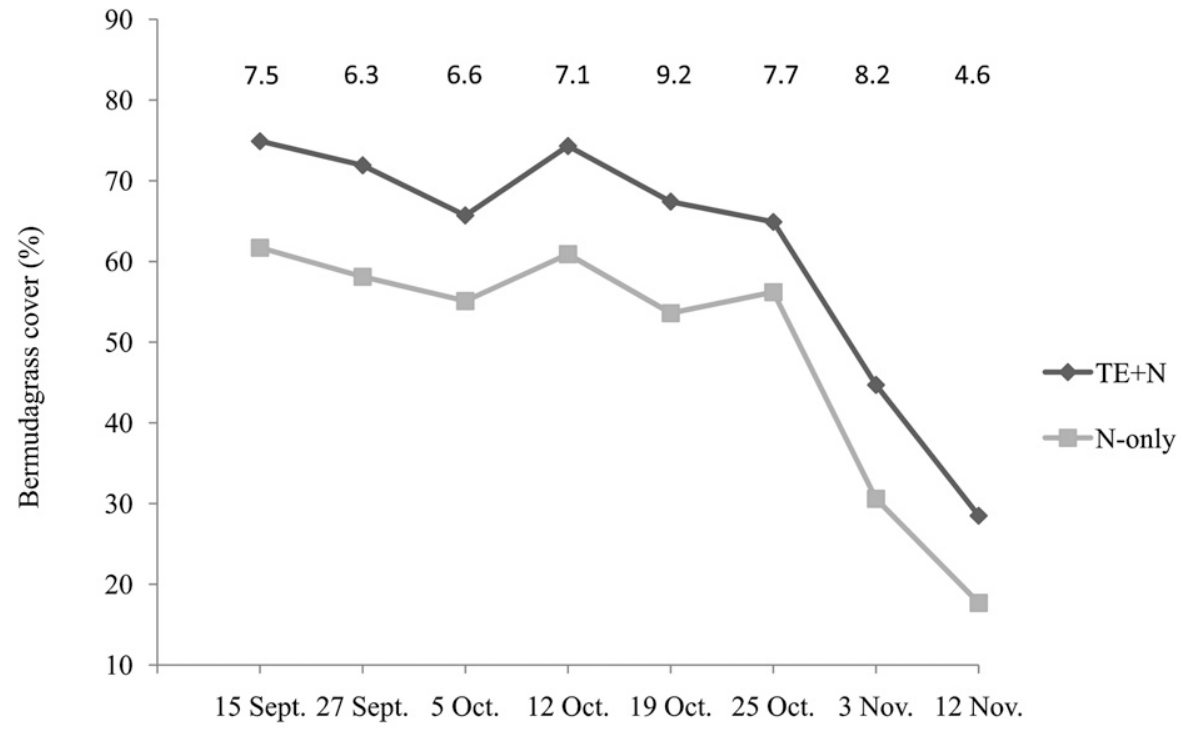

Observation date

Fig. 2. The main effects of applications of $0.09 \mathrm{lb} /$ acre $\left(0.101 \mathrm{~kg} \cdot \mathrm{ha}^{-1}\right)$ a.i. trinexapac-ethyl (TE) every 3 weeks throughout the 2004 growing season on visual estimations of percentage of bermudagrass cover during applications of simulated athletic traffic equivalent to three games per week with the Brinkman traffic simulator. All plots received nitrogen (N) applied at $44 \mathrm{lb} / \mathrm{acre}\left(49.3 \mathrm{~kg} \cdot \mathrm{ha}^{-1}\right) \mathrm{N}$ every 2 weeks. Traffic treatments began on 6 Sept. 2004 and continued until 12 Nov. 2004. Data are across six seeded bermudagrass cultivars (Riviera, Princess 77, Transcontinental, Savannah, Yukon, and SWI-1012). Numbers above the curves indicate the least significant difference (LSD) value at $P<0.05$ for each observation date.

(Munshaw et al., 2001) on 23 June 2004 and 17 June 2005. Germination blankets were used to cover the plots, and irrigation was applied as needed to encourage and enhance germination. Germination occurred on 29 June 
2004 and 21 June 2005. Plots were mowed using a reel-type mower (model no. 2653A; Deere \& Co., Moline, IL) at $5 / 8$-inch height of cut and a frequency of $5 \mathrm{~d}$ per week during peak growth and $3 \mathrm{~d}$ per week in spring and fall with clippings returned. Irrigation was applied only to prevent dormancy after establishment.

Trinexapac-ethyl (Primo Maxx®; Syngenta, Wilmington, DE) was applied to the appropriate split-plots at label rates and frequencies beginning immediately after the first mowing each year. This resulted in applications of TE at $0.09 \mathrm{lb} /$ acre a.i. applied once every 3 weeks until 1 Sept. each year. Applications of TE were made using a carbon dioxide-powered boom sprayer with 8004 flat fan nozzles (Spraying Systems, Wheaton, IL) with a carrier rate (water) of $52 \mathrm{gal} /$ acre at $30 \mathrm{psi}$. One-half of the split-plots received applications of TE plus nitrogen $(\mathrm{N})$, and the remaining half received $\mathrm{N}$ applications only. The source of $\mathrm{N}$ was urea $(46 \mathrm{~N}-0 \mathrm{P}-0 \mathrm{~K})$ and was applied by hand to all plots at $44 \mathrm{lb} /$ acre $\mathrm{N}$ once every 2 weeks beginning at seeding and until 15 Aug. each year (Munshaw et al., 2001). No other fertilizers were applied as the levels of phosphorus and potassium are inherently high and non-limiting in Maury silt loam soils.

Simulated athletic traffic was applied by a Brinkman traffic simulator (BTS) (Cockerham and Brinkman, 1989). Two passes were made with the BTS across all plots three times per week, once each on Mondays, Wednesdays, and Fridays. This traffic regime is roughly equivalent to turf damage from three American football games per week. Traffic treatments were applied regardless of weather and soil moisture status. Traffic treatments began on 6 Sept. 2004 and 7 Sept. 2005, and continued until 12 Nov. 2004 and 31 Oct. 2005.

Turfgrass quality was rated visually before initiation of traffic treatments using a scale of 1 to 9 , where $1=100 \%$ dead turf, $9=$ optimum quality, and $5=$ minimal acceptable quality. Turfgrass quality is a combination of several characteristics, including texture, density, color, and uniformity. Visual estimations of percentage of bermudagrass cover (PBC) of split-plots were recorded about once per week during the trafficking periods in both years. Data were analyzed using PROC GLM of SAS (version 9.1; SAS Institute, Cary, NC). Means of turf quality and PBC were separated by F-protected least significant difference (LSD) tests.

\section{Results}

Environmental conditions at the experimental site were vastly different between 2004 and 2005. By the end of October, there was a year-to-date difference of $510 \mathrm{~mm}$ precipitation between the 2 years (Table 1 ). This difference between years is especially critical during the months of October during which bermudagrass growth rates in Kentucky have significantly declined and simulated traffic was

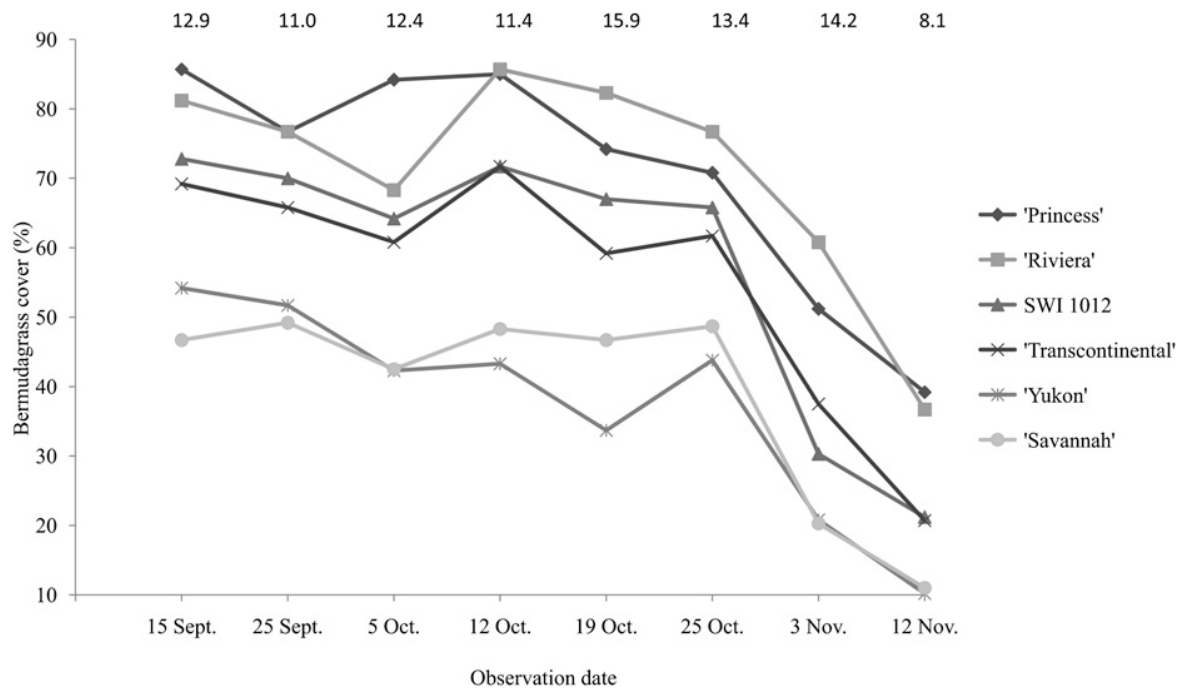

Fig. 3. The main effects of six cultivars on visual estimations of percentage of bermudagrass cover during applications of simulated athletic traffic with the Brinkman traffic simulator equivalent to three games per week in 2004. Traffic treatments began on 6 Sept. 2004 and continued until 12 Nov. 2004. Data are across treatments with and without applications of $0.09 \mathrm{lb} /$ acre $\left(0.101 \mathrm{~kg} \cdot \mathrm{ha}^{-1}\right)$ a.i. trinexapac-ethyl applied every 3 weeks. All plots received applications of nitrogen $(\mathrm{N})$ at $44 \mathrm{lb} /$ acre $\left(49.3 \mathrm{~kg} \cdot \mathrm{ha}^{-1}\right) \mathrm{N}$ every 2 weeks. Numbers above the curves indicate the least significant difference (LSD) value at $P<0.05$ for each observation date.

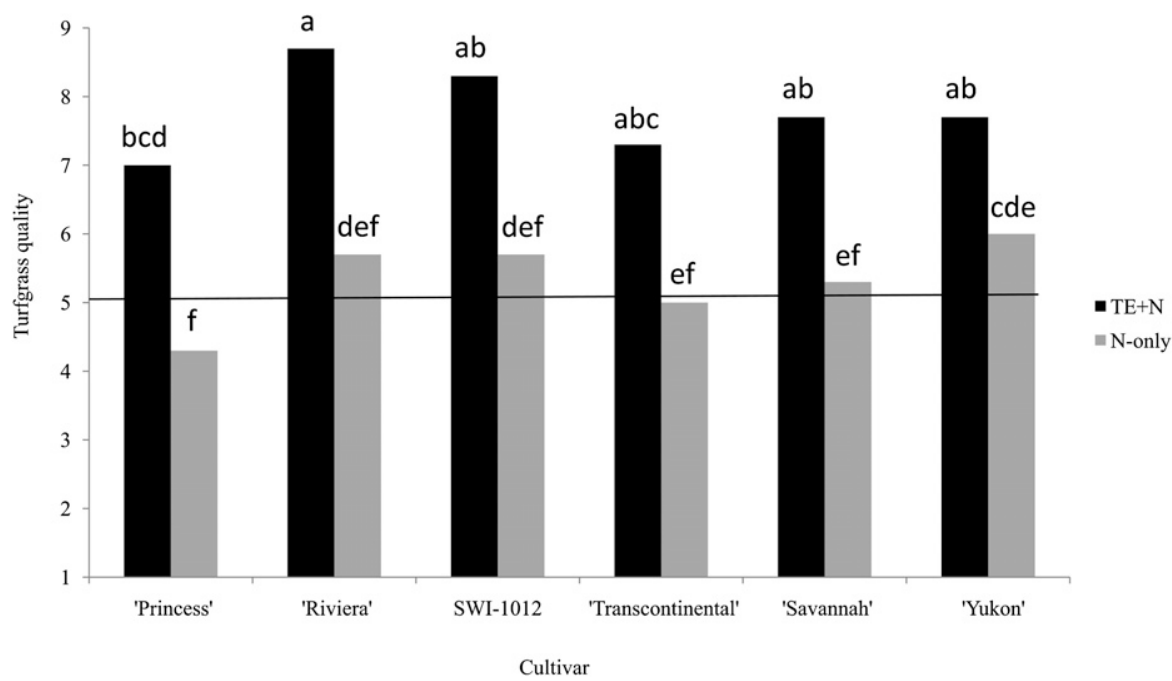

Fig. 4. The effects of six cultivars and applications of $0.09 \mathrm{lb} / \mathrm{acre}\left(0.101 \mathrm{~kg} \cdot \mathrm{ha}^{-1}\right)$ a.i. trinexapac-ethyl (TE) every 3 weeks throughout the 2005 growing season on bermudagrass turfgrass quality rated on a scale of 1 through 9 , where $1=100 \%$ dead turf, $\mathbf{9}=$ optimum quality, and $\mathbf{5}=$ minimum acceptable quality. All plots received nitrogen $(\mathrm{N})$ applied at $44 \mathrm{lb} /$ acre $\left(49.3 \mathrm{~kg} \cdot \mathrm{ha}^{-1}\right) \mathrm{N}$ every 2 weeks. Ratings were collected on 2 Sept. 2005. Horizontal line indicates the minimum acceptable quality rating of "5." Bars labeled with the same letters are not significantly different at $P>0.05$. 
applied weekly in both years. The BTS causes more severe damage to the turf as soil moisture increases. As a result, there were large and significant differences in data collected between years, particularly PBC. Therefore, the data are presented for each year individually.

2004. Turfgrass quality data indicated significant differences due to the main effects of cultivar and TE applications (Table 2). There was also a significant $(P<0.02)$ interaction between cultivars and TE (Fig. 1) in 2004. This is difficult to fully explain. Figure 1 illustrates that applications of TE had a large positive impact on 'Savannah' and no impact at all on 'Yukon'. Both of these cultivars tend to exhibit relatively coarse texture and less tiller density (Morris, 2006). The impact of TE applications on the remaining cultivars was more normal relative to previous work (Fagerness et al., 2002; Richardson, 2002). More importantly, quality data comparing cultivars with or without TE (Fig. 1) confirm earlier work in that 'Princess 77' and 'Riviera' express higher quality than 'Transcontinental', which is greater than 'Yukon' and 'Savannah' (Morris, 2006). Quality of SWI-1012 quality was nearly equal to and not significantly different from 'Transcontinental' (Fig. 1).

Percentage of bermudagrass cover data show that there were no significant interactions $(P>0.05)$ between cultivars and TE applications for any observation date in 2004 (Table 3).

The main effect of TE applications on $\mathrm{PBC}$ was significant on all observation dates $(P<0.01)$ (Table 3$)$. Regardless of cultivar, plots treated with TE maintained higher PBC than plots treated with $\mathrm{N}$-only for the entire rating period (Fig. 2).

The main effect of cultivar on PBC was also significant on all observation dates $(P<0.0002)$. By 12 Nov., $\mathrm{PBC}$ for 'Princess 77 ' and 'Riviera' were statistically equal and significantly greater than SWI-1012 and 'Transcontinental', which were significantly greater than 'Savannah' and 'Yukon' (Fig. 3). The range of $\mathrm{PBC}$ on 12 Nov. was $39.2 \%$ to $10.2 \%$.

2005. Results of statistical tests of turf quality data are presented in Table 2 . The main effects of TE $(P<$ $0.0001)$ and cultivar $(P<0.0349)$ were significant, but there were no significant TE $\times$ cultivar interactions $(P>$ $0.05)$. Applications of TE resulted in significant increases in turfgrass quality for all cultivars (Fig. 4). 'Riviera' exhibited the highest turfgrass quality of 8.7 , which was not significantly greater than SWI-1012, 'Yukon', 'Savannah', or 'Transcontinental'. 'Princess 77' exhibited the lowest turfgrass quality ratings, most likely due to reduced tolerance to the drier than normal conditions as were defined in Table 1. Again, turfgrass quality ratings were comprised of a combination of factors, including color and uniformity. The dry conditions of 2005 had a very negative effect on turfgrass quality ratings as

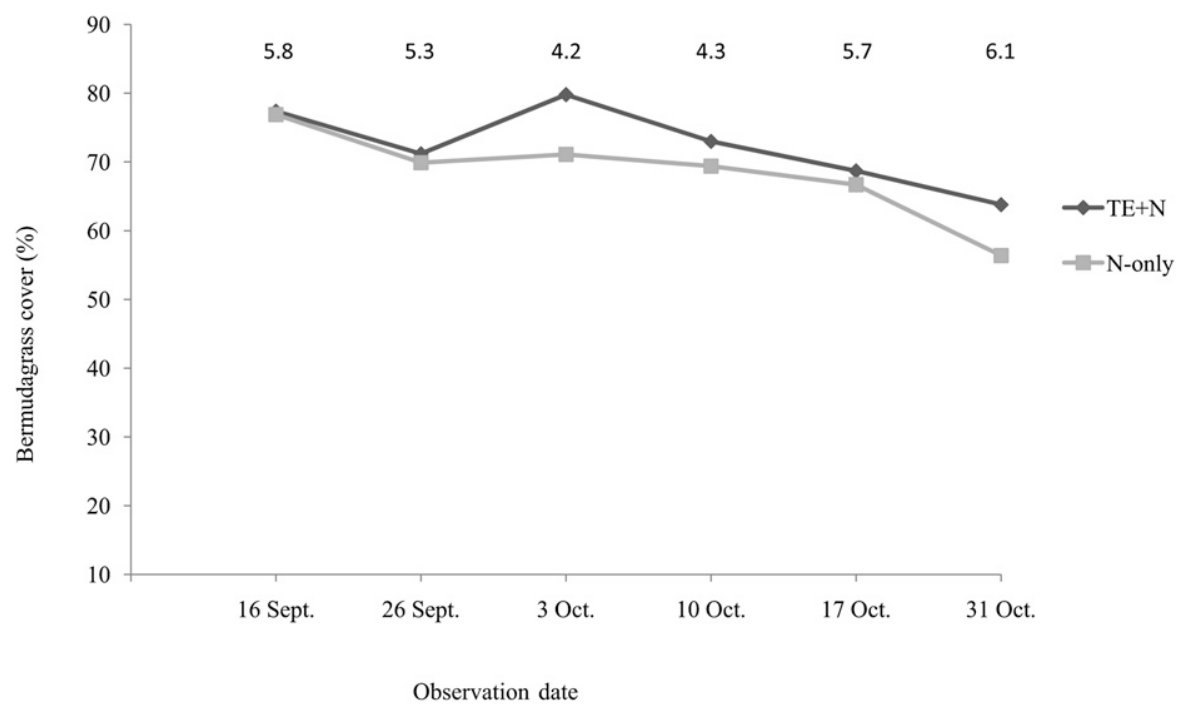

Fig. 5. The main effects of applications of $0.09 \mathrm{lb} / \mathrm{acre}\left(0.101 \mathrm{~kg} \cdot \mathrm{ha}^{-1}\right)$ a.i. trinexapac-ethyl (TE) applied every 3 weeks throughout the 2005 growing season on visual estimations of percentage of bermudagrass cover during applications of simulated athletic traffic with the Brinkman traffic simulator equivalent to three games per week. All plots received nitrogen $(\mathrm{N})$ applied at $44 \mathrm{lb} / \mathrm{acre}\left(49.3 \mathrm{~kg} \cdot \mathrm{ha}^{-1}\right)$ $\mathrm{N}$ every 2 weeks. Traffic treatments began on 7 Sept. 2005 and continued until 31 Oct. 2005. Data are across six bermudagrass cultivars (Riviera, Princess 77, Transcontinental, Savannah, Yukon, and SWI-1012). Numbers above the curves indicate the least significant difference (LSD) value at $P<0.05$ for each observation date.

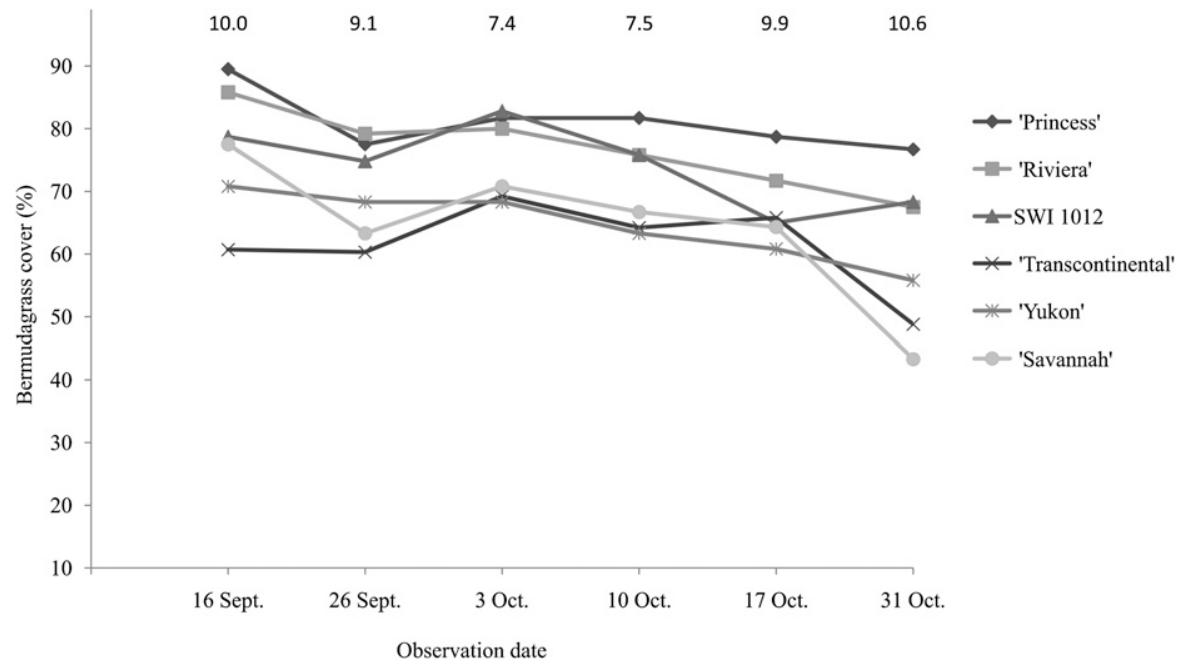

Fig. 6. The main effects of six cultivars on visual estimations of percentage of bermudagrass cover during applications of simulated athletic traffic with the Brinkman traffic simulator equivalent to three games per week in 2005. Traffic treatments began on 7 Sept. 2005 and continued until 31 Oct. 2005. Data are across treatments with and without applications of $0.09 \mathrm{lb} / \mathrm{acre}\left(0.101 \mathrm{~kg} \cdot \mathrm{ha}^{-1}\right) \mathrm{a.i}$. trinexapac-ethyl applied every 3 weeks. All plots received applications of nitrogen $(N)$ at $44 \mathrm{lb} /$ acre $\left(49.3 \mathrm{~kg} \cdot \mathrm{ha}^{-1}\right) \mathrm{N}$ every 2 weeks. Numbers above the curves indicate the least significant difference $(L S D)$ value at $P<0.05$ for each observation date. 
irrigation was applied only to prevent dormancy and not to maintain high turfgrass quality.

Less turfgrass damage from the BTS occurred in 2005 than in 2004, again most likely due to drier soil conditions. However, significant differences were recorded in $\mathrm{PBC}$ for both the main effects of TE applications and cultivar. There were no significant interactions $(P>0.05)$ between TE applications and cultivars for PBC data in 2005 (Table 3). The main effect of TE applications was significant $(P<0.05)$ on two observation dates, 3 and 31 Oct. (Table 3 ). Generally, and including these two significant observations, split-plots treated with $\mathrm{TE}$ exhibited higher PBC than untreated plots (Fig. 5). However, the differences between TE-treated and untreated plots in 2005 were not of the same magnitude as was recorded in 2004.

The main effect of cultivar in 2005 was again significant $(P<0.0149)$ on all observation dates as was recorded in 2004 (Table 3). On the last observation date, 'Princess 77', SWI-1012, and 'Riviera' exhibited significantly $(P<0.05)$ higher PBC than 'Yukon', which was statistically equivalent to 'Transcontinental', which was not significantly different from 'Savannah' (Fig. 6). The range of PBC in 2005 on the last observation date was $76.7 \%$ to $43.3 \%$. This was much greater than the range recorded on the last observation date in $2004(39.2 \%-10.2 \%)$.

\section{Discussion}

Applications of TE at label rates and frequencies resulted in generally higher tolerance to simulated traffic compared with non-treated TE controls. This was true regardless of cultivar. The positive effects of TE applications were exacerbated in 2004 with higher soil moisture and when damage to the turf was more severe. The effects under drier conditions were of lesser magnitude, but sometimes significant $(P<0.05)$ nonetheless. Additionally, it was found that in general, applications of TE also improved turfgrass quality with few exceptions among the cultivars evaluated. This agrees well with previous work (Fagerness et al., 2002; Richardson, 2002).

There were few significant interactions between TE applications and cultivars in turfgrass quality and tolerance to simulated traffic. It is concluded that the effects of TE applications on turfgrass quality and tolerance to simulated traffic are nearly equivalent among the cultivars evaluated in this study when applied at label rates and frequencies. As such, we also conclude that regular applications of TE would be a positive component of management programs for high-use bermudagrass athletic fields, regardless of the cultivar under culture.

There were highly significant differences in PBC, and thus tolerance to simulated traffic, among the cultivars tested in both years of this study. Without exception, the main effect of cultivar was statistically significant $(P<$ 0.05 ) on all observation dates in this study. This was true under more moist (2004) and drier (2005) soil conditions. In general, cultivars with higher tiller density and finer leaf texture tolerated simulated traffic better than coarser textured, less dense cultivars. This agrees very well with the work of Bayrer (2006), who compared three of the same cultivars in this study with 'Quickstand', a common-type, vegetatively propagated cultivar under a very similar simulated traffic regime. These data also agrees well with the work of Goddard et al. (2008) indicating that 'Riviera' and 'Tifway' exhibited higher tolerance to traffic than 'Quickstand'. It is concluded there are highly significant differences among the cultivars tested here in tolerance to simulated traffic. Furthermore, this conclusion might likely apply to other cultivars not tested in this work.

Future research should continue to evaluate current and future commercially available bermudagrass cultivars for tolerance to high levels of traffic, especially before recommending their use to athletic field managers. Additionally, other gibberellic acid-inhibiting plant growth regulators and/or potential combination treatments should be evaluated for effects on bermudagrass tolerance to simulated traffic and turfgrass quality under different management regimes.

\section{Literature cited}

Bayrer, T.A. 2006. Wear tolerance of seeded and vegetatively propagated bermudagrass under simulated athletic traffic. MS Thesis, Univ. Kentucky, Lexington. 27 Jan. 2010. <http://lib.uky. edu/ETD/ukypssc2006t00397/Thesis. pdf $>$.
Cockerham, S.T. and D.J. Brinkman. 1989. A simulator for cleated-shoe sports traffic on turfgrass research plots. California Turfgrass Culture 39:9-10.

Ervin, E.H. and X. Zhang. 2007. Influence of sequential trinexapac-ethyl applications on cytokinin content in creeping bentgrass, kentucky bluegrass, and hybrid bermudagrass. Crop Sci. 47:2145-2151.

Fagerness, M.J., F.H. Yelverton, D.P. Livingston, III, and T.W. Rufty, Jr. 2002. Temperature and trinexapac-ethyl effects on bermudagrass growth, dormancy, and freezing tolerance. Crop Sci. 42:853-858.

Goddard, M.J.R., J.C. Sorochan, J.S. McElroy, D.F. Karcher, and J.W. Landreth. 2008. The effects of crumb rubber topdressing on hybrid kentucky bluegrass and bermudagrass athletic fields in the transition zone. Crop Sci. 48:2003-2009.

McCullough, P.E., H. Liu, L.B. McCarty, and J.E. Toler. 2007. Trinexapac-ethyl application regimes influence growth, quality, and performance of bermudagrass and creeping bentgrass putting greens. Crop Sci. 47:2138-2144.

McCullough, P.E., H. Liu, L.B. McCarty, T. Whitwell, and J.E. Toler. 2006a. Nutrient allocation of 'TifEagle' bermudagrass as influenced by trinexapac-ethyl. J. Plant Nutr. 29:273-282.

McCullough, P.E., H. Liu, L.B. McCarty, T. Whitwell, and J.E. Toler. 2006b. Bermudagrass putting green growth, color, and nutrient partitioning influenced by nitrogen and trinexapac-ethyl. Crop Sci. 46:1515-1525.

Morris, K.N. 2006. Turfgrass quality ratings of bermudagrass cultivars grown at twelve locations in the U.S. Final Rpt. NTEP No. 07-10. 27 Jan. 2010. <http:// www.ntep.org/data/bg02/bg02_07-10f/ bg0207ft0la.txt>.

Munshaw, G.C., D.W. Williams, and P.L. Cornelius. 2001. Management strategies during the establishment year enhance production and fitness of seeded bermudagrass stolons. Crop Sci. 41:1558-1564.

Powell, A.J., Jr. 2007. Sports traffic: How much is too much? 27 Jan. 2010. <http:// www.uky.edu/Ag/ukturf/Athletic\% 20Field\%20Pubs/sports\%20turf\%20traffic. pdf>.

Richardson, M.D. 2002. Turf quality and freezing tolerance of 'Tifway' bermudagrass as affected by late-season nitrogen and trinexapac-ethyl. Crop Sci. 42:16211626.

Samaranayake, H., T.J. Lawson, and J.A. Murphy. 2008. Traffic stress effects on bentgrass putting green and fairway turf. Crop Sci. 48:1193-1202. 